\title{
Análise temporal da microbacia Mariana no município de Alta Floresta, Mato Grosso
}

\author{
Amauri Bambolim ${ }^{1}$, Abilene Rodrigues Donde ${ }^{1}$ \\ ${ }^{1}$ Universidade do Estado de Mato Grosso, Campus de Alta Floresta, Alta Floresta, Mato Grosso, Brasil. E-mail: \\ amauribambolim@outlook.com, bilene06@gmail.com
}

Recebido: 19/04/2017; Aceito: 08/07/2017

\section{RESUMO}

$\mathrm{O}$ uso do sensoriamento remoto tem sido amplamente utilizado por pesquisadores a fim de obter melhores resultados sobre a constante dinâmica da cobertura vegetal. O presente trabalho teve como objetivo realizar uma análise temporal utilizando técnicas de sensoriamento remoto da Microbacia Mariana, localizada no município de Alta Floresta - MT. Foram utilizadas 3 imagens do satélite Landsat 5 sensor TM dos anos de 1990, 2000 e 2010 e uma imagem do satélite Landsat 8 sensor OLI do ano de 2016. Para a classificação das imagens foi utilizado o classificador não supervisionado máxima verossimilhança para a obtenção da classe Floresta e a classe Uso Alternativo do Solo. A análise demonstrou que os anos de 1990, 2000, 2010 e 2016 apresentaram 54\%, 25,5\%, $27,25 \%$ e $25,8 \%$ respectivamente de cobertura de floresta nativa e $68,5 \%, 48,13 \%, 60,41 \%$ e $62,15 \%$ de Área de Preservação Permanente (APP), preservada nos anos de 1990, 2000, 2010 e 2016 respectivamente. Houve uma degradação maior entre os anos de 1990 e 2000 e posterior paralização no desflorestamento da região com um aumento significativo das áreas de APPs, após o ano 2000.

Palavras-chave: Geotecnologia, Sensoriamento Remoto, Bacia Hidrográfica

\section{Temporary analysis of Mariana microbacin in the municipality of Alta Floresta, Mato Grosso.}

\begin{abstract}
The use of remote sensing has been used extensively by researchers in order to get better results on the dynamics of the vegetal cover. The present paper had as objective to perform a temporal analysis using remote sensing techniques of Mariana Microbasin, located in the municipality of Alta Floresta-MT. Three images of the Landsat 5 sensor TM of the years 1990, 2000 and 2010 and one image of the satellite Landsat 8 OLI sensor of the year 2016. For the classification of images was used the unsupervised maximum likelihood classifier for obtaining the class forest and the alternative use of soil class. The analysis showed that the years 1990, 2000, 2010 and 2016 presented $54.5 \%, 25.5 \%, 27.25 \%$ and $25.8 \%$ respectively of native forest cover and $68.5 \%, 48.13 \%, 60,41 \%$ and 62,15\% of Permanent Preservation Area (PPA) preserved in the years of 1990, 2000, 2010 and 2016 respectively. There was a greater degradation between the years 1990 and 2000 and later paralysis without deforestation of the region with a significant increase of the areas of PPAs, after the year 2000.
\end{abstract}

Key words: Geotechnology, Remote sensing, Hydrographic Basin. 
O constante aumento de atividades antrópicas ao longo dos séculos tem causado grandes impactos ao meio ambiente e provocado um rápido esgotamento dos recursos naturais. Essa situação tem levado pesquisadores a elaborar técnicas e estratégias para refrear a degradação ambiental e garantir a continuidade da vida humana no planeta (ALMEIDA et al., 2013).

Neste contexto, o uso da Geotecnologia com seus recursos de monitoramento por sensor remoto pode ser amplamente utilizado para acompanhar as atividades humanas no meio ambiente. Por meio de análises utilizando imagens de satélites propõe as melhores maneiras de uso e ocupação do solo e recuperação de áreas degradadas (TANCREDI, et al. 2012); esta tecnologia denominada Sensoriamento Remoto permite a obtenção de imagens e outros dados da superfície terrestre por meio da captação da energia refletida da superfície terrestre (FLORENZANO, 2011). As técnicas de sensoriamento remoto permitem o estudo do processo evolutivo de uma região por meio de análises temporais de imagens de satélites. Tais sistemas podem estabelecer comparações entre vários períodos de uma mesma região, podendo desta maneira, auxiliar no monitoramento da área de interesse (TANCREDI, et al. 2012).

Desta forma, o mapeamento das bacias hidrográficas e suas áreas de preservação permanentes (APP) é de grande importância para a fiscalização da paisagem, pois são áreas frágeis e frequentemente ameaçadas por perturbações antrópicas nas quais as escalas temporais e espaciais são fundamentais para o seu monitoramento (COUTINHO, et al. 2013).

O presente trabalho teve como objetivo realizar uma análise temporal utilizando técnicas de sensoriamento remoto da Microbacia Mariana no município de Alta Floresta, Mato Grosso, entre os anos de 1990 e 2016 . A área de estudo localiza-se no extremo norte do Estado de Mato Grosso, no município de Alta Floresta - MT, sob as coordenadas geográficas $09^{\circ} 02^{\prime} 29^{\prime \prime}$ a $11^{\circ} 15^{\prime}$, $45^{\prime}$ "de latitude sul e $56^{\circ} 44^{\prime} 55^{\prime \prime}$ a $58^{\circ} 45^{\prime} 10^{\prime \prime}$ de Longitude Oeste (Figura 1). A precipitação pluviométrica da região é de 2000 a $2500 \mathrm{~mm}$ ao ano. O clima segundo a classificação de Köppen é chuvoso com nítida estação seca, tipo Awi. A flora do município é formada principalmente por Floresta Ombrófila Aberta e Densa e uma parte de Cerrado. A vegetação do tipo Cerrado se localiza na região sul do município e a Floresta Ombrófila Densa no extremo Norte, sendo o restante do município coberto por Floresta Ombrófila Aberta. (FERREIRA, 2001).

A Microbacia Mariana exerce papel importante para a população urbana de Alta Floresta - MT pois suas nascentes formam o rio Taxidermista, corpo d'água responsável por prover a água captada pela empresa de saneamento que distribui ao núcleo urbano.

Para a realização deste trabalho foram utilizadas as imagens dos anos de 1990, 2000, 2010 e 2016 tiradas no período do mês de agosto; período de seca da região e consequentemente com baixa incidência de nuvens. Os anos para análise foram escolhidos com base em mudanças importantes nos processos de colonização da região, sendo o ano de 1990 o inicio de um forte avanço da pecuária e agricultura no município. No ano 2000 ocorre o inicio de ações para tirar Alta Floresta da lista dos municípios que mais se praticava o desmatamento; 2010 marca o início de uma década de ações de preservação e a partir de 2016 dá-se o fortalecimento de preservação e recuperação da microbacia. As imagens dos anos de 1990 a 2010, são provenientes do Sensor TM/Landsat 5 e a imagem do ano de 2016 foi adquirida do Sensor OLI/Landsat 8; o satélite LandSat 5 foi desativado em 2013.

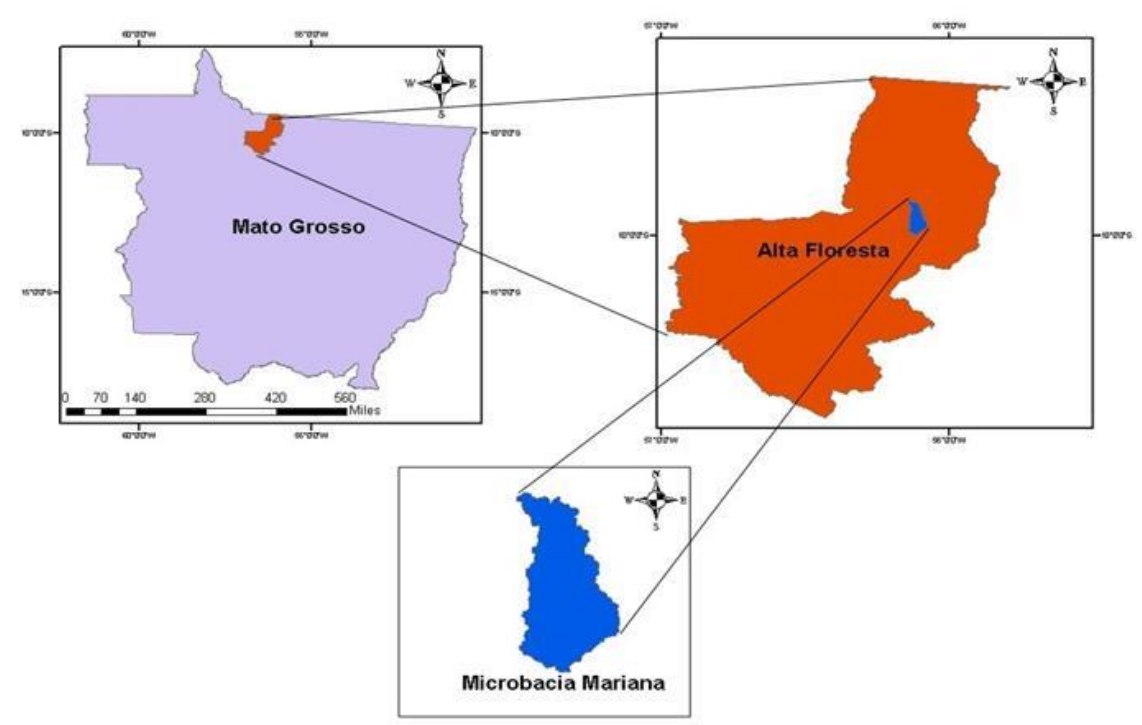

Figura 1. Localização da Microbacia Mariana no Município de Alta Floresta - MT. 
A composição de bandas coloridas $(\mathrm{R}, \mathrm{G}, \mathrm{B})$ para o Sensor TM/Landsat 5 foram as Bandas 3, 4, 1. E Sensor OLI/Landsat 8 foram as bandas 3, 4, 2. Para a realização da análise temporal por meio de imagens de satélite utilizou-se o software Arcgis 10.1. Foi realizada a classificação supervisionada máxima verossimilhança onde se obteve duas classes, a classe Floresta e a classe Uso Alternativo do Solo. A delimitação das APPs fundamentou-se no Novo Código Florestal Brasileiro (SODRE, 2013) cujas normas determinam APP de $30 \mathrm{~m}$ para rios com menos de $10 \mathrm{~m}$ de largura e para nascentes APP de $50 \mathrm{~m}$.

A análise temporal indicou uma diminuição acentuada da cobertura florestal na Microbacia Mariana; a imagem classificada do ano de 1990 (Figura 2) apresentou maior área de floresta, porém ao longo do período estudado houve mudança na paisagem da
Microbacia, principalmente entre os anos de 1990 e 2000. No ano 2000 (Figura 3) houve um aumento considerável da classe Uso Alternativo do Solo em detrimento da classe Floresta especificamente da área da Microbacia Mariana.

Cunha (2006) confirma o avanço do desmatamento Microbacia Mariana e explica que tal período foi marcado pelo avanço da agricultura e pecuária na região. Este aumento pode ser explicado também pela escassa política de fiscalização por parte do governo na região na década de 1990 incentivando cada vez mais ações ilícitas de desmatamento e ocupação de áreas do norte do Estado do Mato Grosso. Segundo Oliveira et al. (2008) essa degradação normalmente parte de agentes isolados que em conjunto provocam impactos de grande escala.

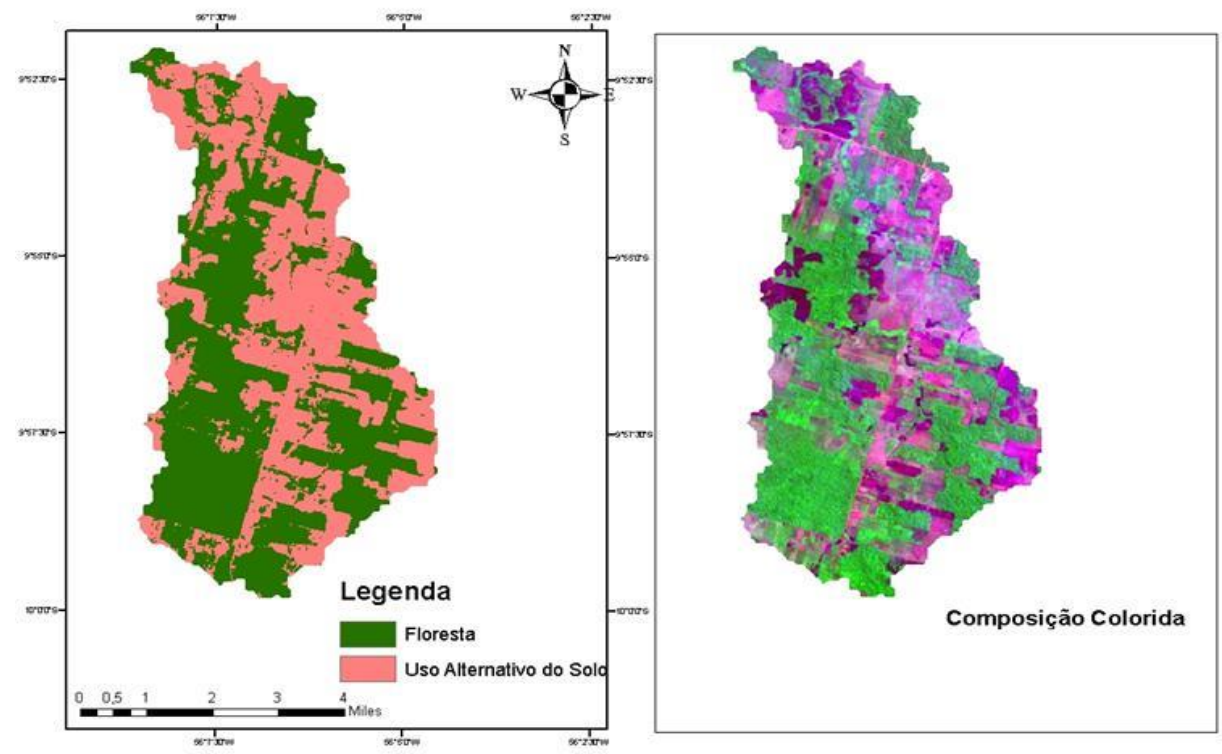

Figura 2. Mapa de classificação do solo da Microbacia Mariana e composição colorida da imagem Landsat 5 do ano de 1990

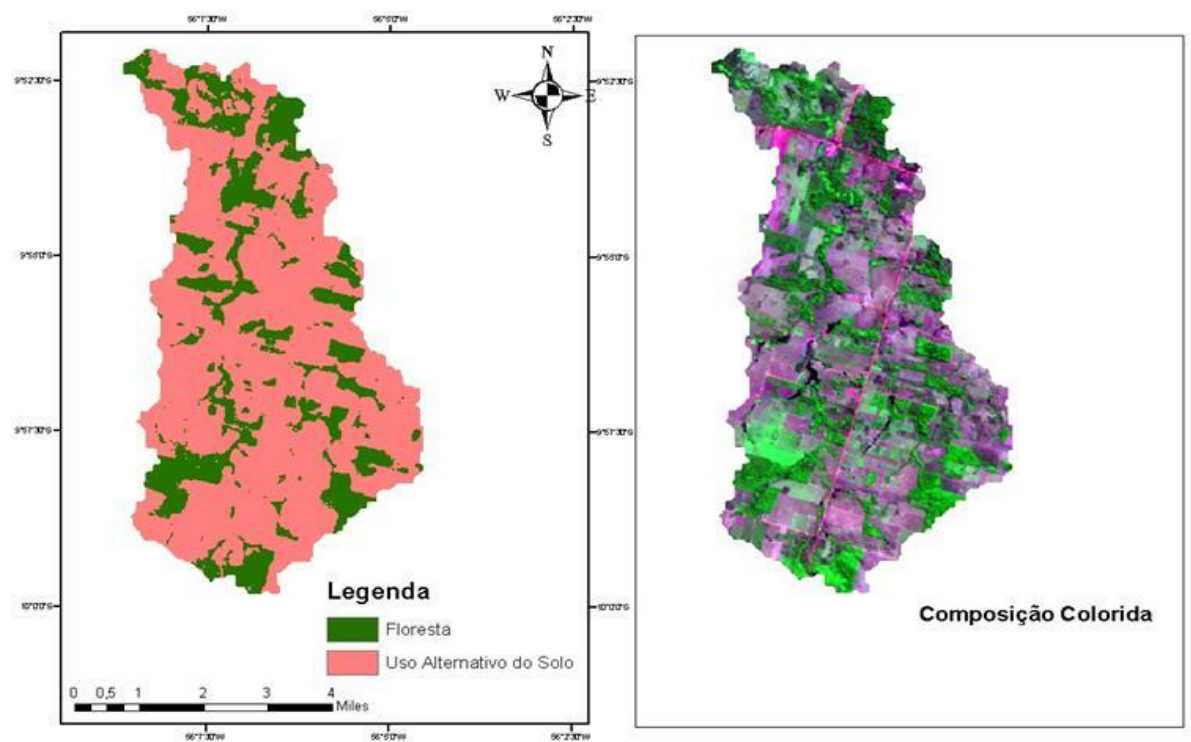

Figura 3. Mapa de classificação do solo da Microbacia Mariana e composição colorida da imagem Landsat 5 do ano de 2000. 
Quando comparado o ano de 2010 (Figura 4) ao ano de 2000 (Figura 3), não houve um aumento significativo de área desflorestada indicando que nestes 10 anos houve uma paralisação no aumento da conversão de florestas em uso alternativo do solo. A estabilização do desflorestamento a partir do ano 2000 pode ser explicado pelo aumento da fiscalização ambiental na região como por exemplo a Operação Curupira da Policia Federal e um esforço político para tirar o município de Alta Floresta - MT da lista dos municípios com maior ocorrência de desmatamento do país. No entanto, apesar de não haver continuidade na abertura de novas áreas para uso alternativo do solo não houve também regeneração das áreas já abertas e desmatadas. Desta forma este quadro persiste na análise da imagem do ano de 2016 (Figura 5).

No ano de 1990, havia cerca de $54 \%$ da área da Microbacia Mariana coberta por mata nativa; este valor diminui drasticamente para $25,5 \%$ no ano 2000 observando-se pequeno aumento em 2010 (27,25\%) chegando em 2016 a 25,8\%, ou seja, uma diminuição inicial e posterior estabilização (Figura 6).

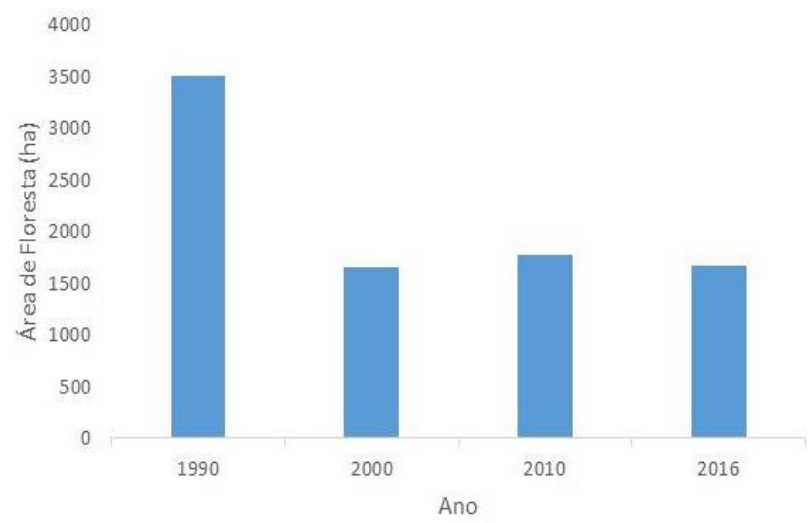

Figura 6. Gráfico da cobertura de floresta nativa entre os anos de 1990 a 2016 da Microbacia Mariana.

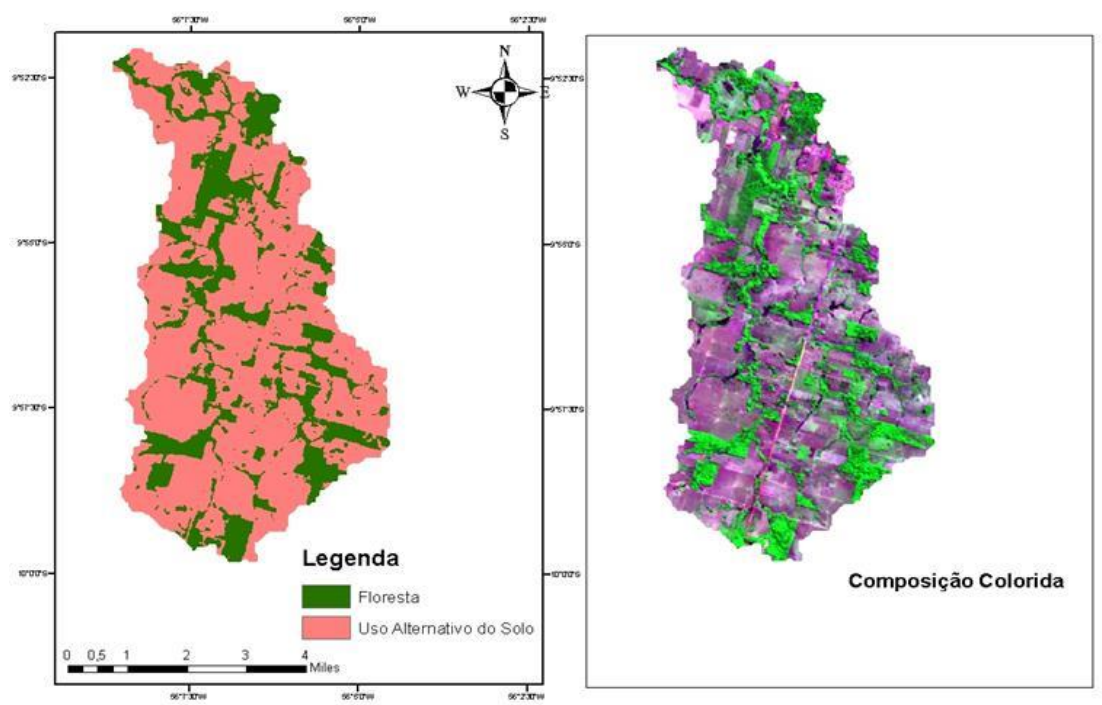

Figura 4. Mapa de classificação do solo da Microbacia Mariana e composição colorida da imagem Landsat 5 do ano de 2010.

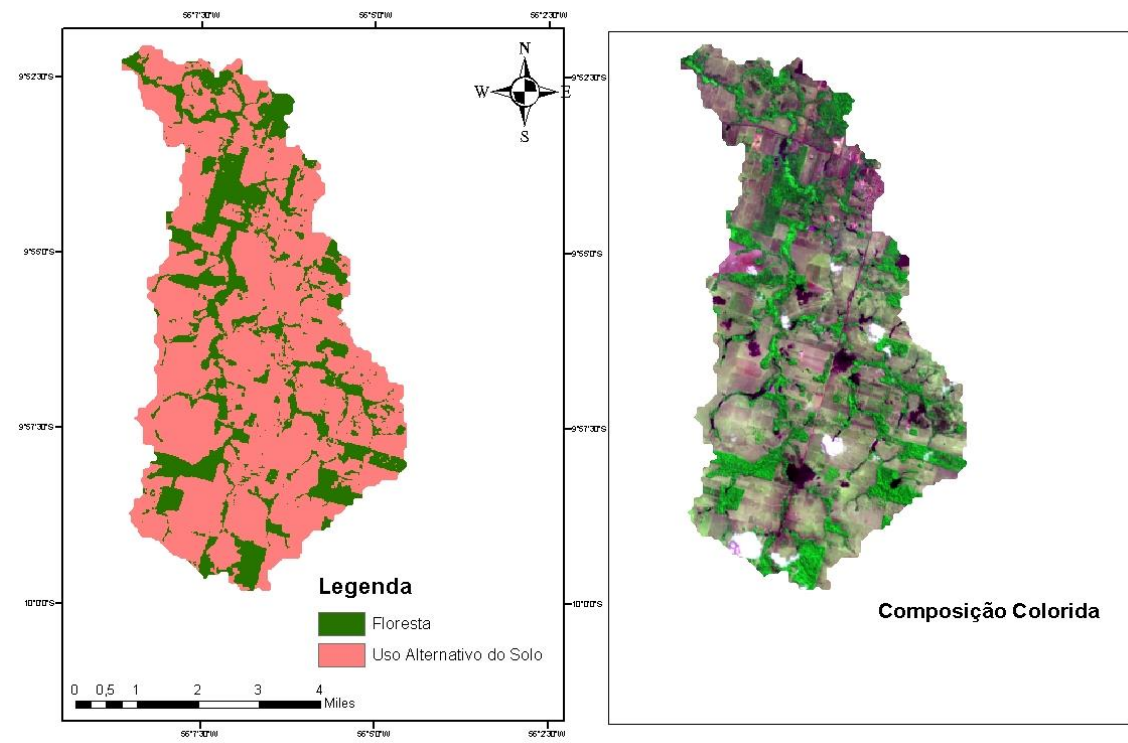

Figura 5. Mapa de classificação do solo da Microbacia Mariana e composição colorida da imagem Landsat 8 do ano de 2016. 
A microbacia Mariana possui uma área de APP hídrica de aproximadamente 687 ha. A análise temporal demonstrou que em 1990 havia 68,5\% da área de APP preservada; diminuindo para 48,13\% no ano 2000. Contudo, em 2010 a área de preservação permanente subiu para 60,41 e posteriormente para $62,15 \%$ em 2016.

O aumento considerável da área de mata ciliar preservada a partir do ano 2000 (Figura 7), se deve principalmente à implantação do projeto Olhos d'água da Amazônia que desenvolveu ações para recuperação das áreas de APPs do município de Alta Floresta - MT, inclusive a Microbacia Mariana, principal responsável pelo abastecimento de água do núcleo urbano do município.

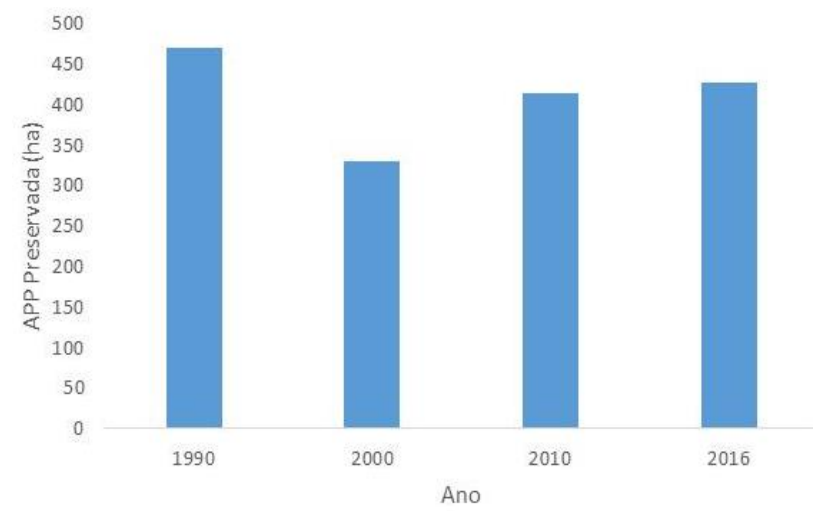

Figura 7. Gráfico da área de APP preservada entre os anos de 1990 a 2016 da Microbacia Mariana.

Apesar do esforço para garantir a preservação das áreas de APP da Microbacia Mariana, segue longe da marca ideal de $100 \%$ de mata ciliar protegida, conforme as leis ambientais vigentes. A total preservação dessas áreas garante também a manutenção dos recursos hídricos indispensáveis para a sobrevivência de seres humanos e animais. De acordo com Jacovine et al. (2008) a degradação das áreas de APP não atinge somente os recursos hídricos, mas também a diversidade da fauna no ecossistema, pois a degradação constitui uma ameaça ao habitat natural dos seres vivos destruindo corredores ecológicos, principais responsáveis pelo fluxo gênico.

Neste contexto torna-se necessário uma fiscalização eficaz e constante produção de trabalhos acadêmicos com objetivo de monitorar as matas ciliares garantindo assim a preservação e recuperação destas áreas.

A análise temporal indicou um aumento na classe Uso Alternativo do Solo entre os anos de 1990 e 2000. Entre os anos de 2000 e 2010, não houve aumento da classe Uso Alternativo do Solo. Os anos de 2010 a 2016 não apresentou mudanças consideráveis nas classes analisadas. As áreas de APP apresentaram grande redução entre os anos de 1990 e 2000 e boa recuperação nos anos de 2010 a 2016, atingindo patamares próximos aos do ano de 1990.

\section{Referências Bibliográficas}

ALMEIDA, A. N; ANGELO, H.; SILVA J. C. G. L.; SOARES, P. R. C.; KANIESKI, M. R. Efetividade do Aumento da Área de Reserva Legal por Meio de Instrumento Legal na Taxa de Desmatamento da Amazônia Brasileira. Floresta e Ambiente, Seropédica-RJ, v. 20, n. 2, p. 143-148, 2013.

COUTINHO, L. M.; ZANETTI, S. S.; CECÍlIO, R. A.; GARCIA, G. O.; XAVIER, A. C. Usos da Terra e Áreas de Preservação Permanente (APP) na Bacia do Rio da Prata, Castelo-ES. Floresta e Ambiente, Seropédica-RJ, v. 20 n. 4, p. $425-434,2013$.

CUNHA, J. M. P. Dinâmica migratória e o processo de ocupação do Centro-Oeste brasileiro: o caso de Mato Grosso. Revista Brasileira de Estudos de População, Rio de JaneiroRJ, v. 23, n. 1, p. 87-107, 2006.

FERREIRA, J. C. V. Mato Grosso e Seus Municípios. Cuiabá-MT: Secretaria de Estado de Educação, 2001. p. 365.

FLORENZANO, T. G. Iniciação em Sensoriamento Remoto. 3. ed. São Paulo-SP: Oficina de Textos, 2011. 128 p.

JACOVINE, L. A. G.; SILVA, M. L.; VALVERDE, S. R.; FILHO, E. I. F.; COELHO, F. M. G.; PAIVA, H. N. Quantificação das áreas de preservação permanente e de reserva legal em propriedades da bacia do Rio Pomba-MG. Revista Árvore, Viçosa-MG, v. 32, n. 2, p. 269-278. 2008.

OLIVEIRA, P. C. A.; RODRIGUES, G. S. S. C.; RODRIGUES, S. C. Fragilidade ambiental e uso do solo da Bacia Hidrológica do Córrego Pindaíba, Uberlândia-MG, Brasil. Revista Ambiente e Água, Taubaté-SP, v. 3, n. 1, p. 54-69, 2008.

SODRÉ, A. A. Novo Código Florestal Comentado: Lei 12.651/2012, Leme-SP: Mizuno, 2013. 249 p.

TANCREDI, N. S. H.; ALMEIDA, J. R.; LINS, G. A.; GUERRA, A. J. T.; JORGE, M. C. O. Uso de geotecnologias em laudos periciais ambientais: estudo de caso no município de Jacundá, Pará. Revista Geografar, Curitiba-PR, v. 7, n. 1, p. 1-19, 2012. 